\title{
Hereditary benign intraepithelial dyskeratosis
}

INSERM

\section{Source}

INSERM. (1999). Orphanet: an online rare disease and orphan drug data base. Hereditary benign intraepithelial dyskeratosis. ORPHA:352657

A rare, genetic, superficial corneal dystrophy disease characterized by white, elevated, epithelial plaques located on the bulbar conjunctiva (sometimes with encroachment of the cornea) and oral mucosa (in any part of the oral cavity), associated with dilated, hyperemic, conjunctival blood vessels, observed mainly in Haliwa-Saponi Native American descendents. Patients may be asymptomatic or present with ocular itching, superficial corneal scarring, excessive lacrimation, photophobia and visual loss due to corneal opacity. Histologically, both ocular and oral lesions display acanthosis with hyperkeratosis and prominent dyskeratosis. 